\title{
Assessment of Coral Reef Environment Using Associated Fishes Along South-East Coast of India
}

\author{
Jayapraba J., Muthu M.S. and Sathya A.C.R.* \\ Centre of Advanced Study in Marine Biology, Annamalai University, India \\ *acrathish@gmail.com
}

\begin{abstract}
In the present study, totally 162 species of coral reef associated fishes, belonging to 17 orders, 64 families and 94 genera have been recorded in Cuddalore, Parangipettai and Nallavadu reefs. The study was conducted for a period of two years from January 2012 to December 2013. In Cuddalore, during 2012 a total number of 138 species of coral reef associated fishes belonging to 83 genera, 55 families and 17 orders were recorded, and in 2013, as many as 131 species belonging to 76 genera, 51 families and 14 orders were recorded. In Parangipettai, 127 species of coral reef associated fishes belonging to 78 genera, 48 families and 13 orders were recorded during 2012, and in 2013, 120 species belonging to 73 genera, 45 families and 12 orders were recorded. In Nallavadu, 117 species of coral reef associated fishes were recorded in 2012. These belong to 77 genera, 51 families and 17 orders; whereas, in 2013, totally 112 species belonging to 75 genera, 52 families and 17 orders were recorded. Considering the family-wise distribution, families such as Carangidae, Serranidae and Lutjanidaeare were found dominant with 22, 15 and 12 species respectively, followed by Haemulidae and Mullidae (6 species each), Acanthuridae, Nemipteridae, Siganidae and Synodontidae (4 species each), Clupeidae, Ephippidae, Lethrinidae and Sphyraenidae (3 species each) and other families with less than three species.

Shannon Wiener diversity index recorded was in the range of 5.775 (during pre-monsoon period in 2013 at Cuddalore) -4.326 (during summer in 2012 at Nallavadu). In Margalef's richness index, the maximum of 13.74 was recorded in Cuddalore during pre-monsoon in 2012 and the minimum of 7.975 in Nallavadu during monsoon in 2013. In taxonomic diversity among the three regions, the maximum of 55.86 was recorded in Parangipettai and minimum (51.55) was found in Nallavadu during the pre-monsoon period in 2012. In phylogenetic diversity the maximum of 4217 Cuddalore and a minimum of 2467 were recorded in Nallavadu during summer in 2013. The higher values recorded in all diversity indices clearly showed the good health of the coral reef environment in the study area.
\end{abstract}

Keywords: Health, Coral reef, Environment, Diversity indices, Fishes

Proceedings of the International Forestry and Environment Symposium 2016, Department of Forestry and Environmental Science, University of Sri Jayewardenepura, Sri Lanka. 